\title{
An Event Semantic Structure Analysis of Shona Causative Constructions
}

\author{
Victor Mugari \\ Beijing Language and Culture University \\ Building number 7, Room 102, Number 15 Xueyuan Road \\ Haidian District, Beijing 100083, China \\ Tel: 86-108-230-1947Ｅ-mail: vicky.mug@gmail.com/vickymugy2004@yahoo.com
}

Received: March 9, 2012 Accepted: March 28, 2012 Published: June 1, 2012

doi:10.5296/ijl.v4i2.1488ＵRL: http://dx.doi.org/10.5296/ijl.v4i2.1488

\begin{abstract}
This paper analyses the semantics of causative constructions in Shona, employing the Event structure Approach (Davidson, D. (1967). "The Logical Form of Action Sentences."). We argue that Shona can be accounted well through the neo-Davidsonian approaches particularly because of the need to accommodate the agglutinative nature of the language. In this paper, causative constructions are taken as accomplishment verbs whose predication is a complex one. The causative is a complex event construction that is made up of subevents that are constrained through time-participant connectedness, making sure that the complex event is a sum of different subevents, which upon their union, form a single complex predicate that has its own combinatorial capacity, subcategorizing for its own arguments.
\end{abstract}

Keyword: Event semantics, Shona, Causative constructions, Complex predicate 


\section{NI Macrothink}

\section{Introduction}

This paper accounts for the semantics of causative constructions in Shona. Shona is a Bantu language coded Zone S.10 in Guthrie's (1948, 1967-71) classification, native to the Shona people of Zimbabwe, southern Zambia and parts of Mozambique. Zone S Bantu languages belong to the Southern Bantoid languages, which are a subgroup of the Bantoid languages, which in turn form a subgroup of the Niger-Congo language family. Apart from the language, the term Shona is also used to identify people who speak one of the Shona language dialects, namely Zezuru, Karanga, Manyika, Ndau and Korekore. It has a complex derivational and inflectional system, manifesting agglutinative morphology and uses affixation as a major mechanism for word formation. Shona is a head-initial SVO language.

Causative constructions refer to predicates formed by a combination of a causative event and an underlying predicate. Morphologically, the Shona causative is characterized by the presence of the extensions /-es-/, /-is-/ and /-y/ that are suffixed to the base verb and cognates of these are found in other Bantu languages. Below are examples of base verbs and their causativised counterparts.

\begin{tabular}{|l|l|l|l|}
\hline BASE FORM & GLOSS & CAUSATIVE FORM & GLOSS \\
\hline Rov-a & Beat & Rov-es-a & Cause to beat \\
\hline Idy-a & Eat & Dy-is-a & Cause to eat \\
\hline Bik-a & Cook & Bik-is-a & Cause to cook \\
\hline Kwir-a & Climb & Kwir-is-a/kwidz-a & Cause to climb \\
\hline End-a & Go & End-es-a & Cause to go \\
\hline Rum-a & Bite & Rum-is-a & Cause to bite \\
\hline Roor-a & Marry & Roor-es-a/roodz-a & Cause to marry \\
\hline Seng-a & Carry & Seng-es-a/sengedz-a & Cause to carry \\
\hline Tum-a & Send & Tum-is-a/tunzv-a & Make go \\
\hline Suk-a & wash & Suk-is-a & Cause to wash \\
\hline
\end{tabular}

Figure 1. Causativised transitive verbs

Apart from the morphological causatives, Shona has another type of causatives called 
Analytic $^{1}$ (periphrastic), which like the morphological one is regarded as productive. An analytic causative is defined by Kemmer and Verhagen (1994:117) as a two-verb structure that expresses a predicate of causation and a predicate of effect. These employ certain causative verb meaning 'cause, force, make, have' to name the causing EVENT, followed by verbal complements that name the caused EVENT or effect as exemplified below.

1a) Victor a- it - a kuti Tsvakai a-dy-e.

1a-name 1SM do TV AUX 1a-name 1OM eat TV

'Victor made Tsvakai eat.'

b) Vincent a-it - a kuti Joy a- ty-e.

1a-name 1SM do TV AUX 1a-name 1OM eat TV

'Vincent made Joy to be afraid.'

c) a - konzer-a kuti ndi-chem-e

1SM cause TV AUX 1OM cry TV

'He caused me to cry.'

The two verbs in italics together form the complex causative meaning. The two verbs explicitly name separate yet related EVENTS in such a way that the first EVENT implicates the execution of the second. The causative verb, the first in the sentence, and the lower verb contribute their own syntactic and semantic features such as their subcategorized arguments, their semantic relation, and their background context to a unified entire complex predicate.

The grammar of causative constructions has inspired what is probably one of the most extensive literatures in modern linguistics. Such intensive scrutinies have undoubtedly been provoked partly by the intriguing complexities of causatives. In addition, there seems to have been a tacit recognition by many linguists that an understanding of causatives is fundamental to an understanding of clause structure as a whole (Kemmer and Verhagen 1994:115). Causatives are valence increasing operations, thereby encoding speakers' choice to incorporate an additional element (a cause) into the event description.

\section{The Development of Underlying Event Semantics}

This paper analyses causative constructions in Shona employing the underlying event semantics theory that owes its introduction to linguistics to Donald Davidson. Much work on verbal semantics in the past twenty years or so has been shaped by Davidson's idea to treat events as individuals, as values of variables in first-order logic (Davidson 1967).

Basic logic texts typically assign simple English sentences like (2a) a representation like (b), involving two constants and a binary relation. Davidson (1967) proposes that action sentences like this are not so simple, and involve, in addition, a quantification over events.

\footnotetext{
${ }^{1}$ There is also a third type called lexical causatives. However, the scope of this paper will not allow us to analyze further these two types of causatives.
} 
Davidson's original formulation is given in (c), where an existentially quantified event parameter is simply added to the relational structure of the predicate. The widely-adopted, neo-Davidson position is given in (d), where the verb is distilled into a core unary event predicate, whose participants are linked to the event by means of conjoined binary thematic relations (Higginbotham 1989 and Parsons 1990);

2a. Mary kissed John.

b. $\operatorname{kiss}(m, j)$

c. $\exists \mathrm{e}[\mathrm{kiss}(\mathrm{m}, \mathrm{j}, \mathrm{e})]$ ("There is a kissing of John by Mary.") "Classical Davidson"

d. $\exists$ e[kissing(e) \& Agent $(e, m) \&$ Theme $(e, j)] \quad$ "Neo- Davidson"

"There is a kissing, and it is by Mary, and it is of John."

Davidson's key motivation for introducing events is the analysis of adverbs it offers. Adverbs of many different kinds (manner, duration, location, etc.) are analyzed as predicates of events, allowing a very simple account of how they are semantically integrated into the clause;

3a. Mary kissed John quickly. MANNER

b. $\exists \mathrm{e}[\operatorname{kiss}(\mathrm{m}, \mathrm{j}, \mathrm{e}) \&$ quick$(\mathrm{e}, C)]$

("There is a kissing of John by Mary and it is quick (for such an action).")

4a. Mary kissed John for-an-hour. DURATION

b. $\exists \mathrm{e}[\mathrm{kiss}(\mathrm{m}, \mathrm{j}, \mathrm{e}) \&$ for-an-hour(e)]

("There is a kissing of John by Mary and it is an hour long.")

5a. Mary kissed John in-the-park. LOCATION

b. $\exists \mathrm{e}[\mathrm{kiss}(\mathrm{m}, \mathrm{j}, \mathrm{e}) \&$ in-the-park(e)]

("There is a kissing of John by Mary and it is in the park.")

The Davidsonian event analysis has the interesting property that adverbial predicates are not scopal. Unlike the standard semantics, adverbs are not analyzed as functors applying to VP denotations of the familiar sort. Rather they are simple conjuncts. Our scope-like intuition that "quickly applies to kissed John" in (3a) arises from the fact that VP denotes an event of John-kissing, and quick is true of this whole event.

Another point to note about (3)-(5) is that the event quantifications are represented as unrestricted/unstructured. The existential quantifier attaches to a "flat" structure of co-equal event conjuncts. A number of authors have argued that this aspect of Davidson's analysis is in need of refinement and that in certain cases event quantification is structured into quantifier, restriction and scope.

This therefore requires us to adopt the Neo-Davisonian Event Semantics approach. In this approach, complements can be treated analogously to adjuncts although Kathol et al (2011) 
argue that it is a common and generally unquestioned assumption in much of contemporary linguistics that there is a syntactic distinction between complements and adjuncts, and that these two classes of dependents occupy different tree-configurational positions. The approach however is not peculiar to event semantics as other recent theoretical constructs like Head-driven Phrase Structure Grammar (HPSG) have re-examined the difference between complements and adjuncts too. Hukari and Levine $(1994,1995)$ show that there are no differences between complement extraction and adjunct extraction.

Event verbs are represented as one-place event predicates. The structure events clearly interact with thematic role assignments, with causality and agentivity, and it has implications for syntactic and cross-linguistic properties. Thematic roles are two-place relations linking arguments to the event denoted by the verb for example;

6 The gardener killed the baron at midnight in the park

$$
\exists \mathrm{e}[\mathrm{kill}(\mathrm{e}) \& \quad \operatorname{Agent}(\mathrm{e}, \mathrm{g}) \& \quad \operatorname{PAT}(\mathrm{e}, \mathrm{b}) \& \quad \operatorname{time}(\mathrm{e}, \mathrm{m}) \& \quad \operatorname{location}(\mathrm{e}, \mathrm{p})]
$$

This can be informally translated as that there exist an event $e$ of which the predicate of the event is kill and the Agent of the event is the gardener $g$ and the Patient (PAT) of the event is the baron $b$ and the time of the event is at midnight $m$ and the location of the event is in the park $p$. The existential quantifier has scope over the whole proposition. Neo-Davidsonian semantics allows the partitioning of semantic information into minimal pieces. This paper will adopt the neo-Davidsonian approach, but first traces the origins and development of the semantic study of causative constructions.

According to Shibatani (1976:273), "most comprehensive analysis of the causative construction has been done in the framework of generative semantics". The causative construction provided the generative semanticists, particularly Lakoff (1970) and McCawley (1968) with the most rewarding field of investigation. The generative semantics account would attribute to the sentence 'Mary closes the door' a deep structure like (7) below; 


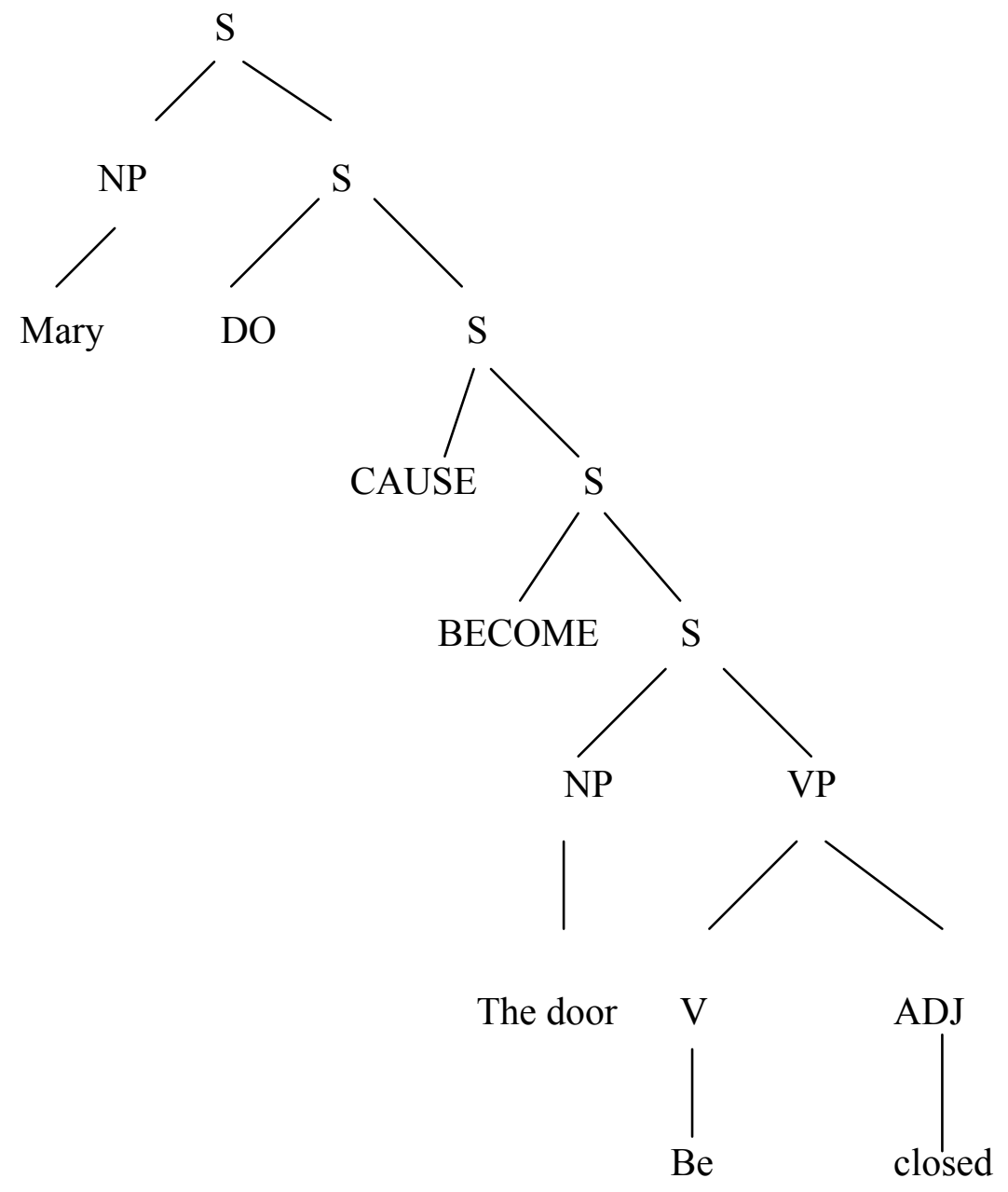

In Generative Semantics, deep structure was treated as a form from which the syntax of the sentence 'Mary closed the door' should be derived. The deep structure displayed was also supposed to picture the semantics of the sentence.

Despite being hailed by many researchers and being adopted in the analysis of a number of languages, the generative semantics approach to the study of causative constructions is not without problems. Some of the problems of the generative semantics demand a certain amount of modification in the semantic structure originally proposed, some point up the need for closer semantic specifications. Other scholars present devastating evidence against the generative semantics approach and vehemently challenge the tenets of generative semantics.

Chomsky (1971), in his quest to displace the generative semantics analysis of causative constructions notes the problems that obtain in thinking of the lexical entry for 'kill' as specifying somehow a phrase marker 'cause to die'. He argues that, similarly, the lexical entry for 'murder' might indicate that it can be inserted by a lexical transformation for the substructure murder=cause to die by unlawful means and with malice aforethought, where the grammatical object is furthermore human. Furthermore, the lexical entry for 'assassinate' might specify further that the object be characterized, elsewhere in the phrase marker, as a reasonably important person. Chomsky is more particularly fascinated with the way in which 
such related concepts as 'kill', murder', and assassinate could be treated in the generative semantics analysis.

According to Parsons (1990), the general framework of generative semantics has been rejected by most linguists for syntactic reasons. He further says that the semantical analysis implicit in the proposal can be considered independently of the framework within which it was first proposed. This implies that somehow the sentence 'Mary closes the door' can be represented as (8) below;

8 Mary DO CAUSE BECOME the door be closed.

Dowty (1979) accounts for causatives within the auspices of Montague Grammar. Dowty's (1979) idea of decomposing predicates has been reformulated in event semantic terms. An event (the macroevent) can be structurally complex and decomposable into particular subevents. Subevents are associated with CAUSE, DO or BECOME predications, or related notions such as preparatory phase, initiating state, process, transition, culmination, consequent or result state. He would analyse the sentence 'Mary closes the door' as (9) below;

$9(\exists \mathrm{P})[(\mathrm{P}($ Mary $)) \mathrm{CAUSE}(\mathrm{BECOME}($ The door is closed $))]$

The general reading is that 'Mary did something that caused the door to become closed'. According to Dowty's analysis, the notions DO, CAUSE and BECOME all take scope over the whole sentence. This would be evidence for a bisentential analysis of causatives against a bievent analysis.

Parsons (1990) adopts the idea behind the proposed analysis of Generative Semanticists and Dowty. The result is that within the underlying events framework, the sentence 'Mary flew the kite' contains quantifications over events, what Mary did and what the kite did, with the translation as $(10 \mathrm{~b})$ below;

10a Mary flew the kite.

b ( $\exists \mathrm{e})\left[\operatorname{Agent}(\mathrm{e}, \mathrm{Mary}) \& \operatorname{Cul}(\mathrm{e}) \&\left(\mathrm{e}^{\prime}\right)\left[\right.\right.$ Flying(e') \& $\operatorname{Cul}\left(\mathrm{e}^{\prime}\right) \&$ Theme(e',kite) \&

$$
\text { CAUSE(e,e')]] }
$$

Informally, there exists an event, the agent of the event is Mary and the event is a culmination one and there exist another event that is a flying event and also a culmination one whose theme is kite and the event is a cause event. The (cul)mination is the final minimal event in an incremental process. It is the event which is the final part of a become event; the upper bound of the become event. The argument of the culmination event is the argument of the become event (i.e. the affected object or theme).

This entails 'The kite flies' with the following translation;

11 ( $\left.\exists \mathrm{e}^{\prime}\right)\left[\right.$ Flying(e’) \& $\operatorname{Cul}\left(\mathrm{e}^{\prime}\right)$ \& Theme(e',kite)]

The idea behind the above analysis has been around for a long time and there are a number of objections to it in the literature that depends on its origins within the particular details of the 
framework of Generative Semantics. Due to space limitations, this paper will not account for the collapse of this linguistic research program of the 1960'and 1970's, occasioned by its contretemps with archrival, 'interpretive semantics', which, while winning the linguistic battle, was therefore transmogrified.

\section{Causative Event Structure}

In spite of the highlighted challenges that Parsons' analysis face, a preliminary application of his approach to Shona data would also expose some anomalies. Let us consider the sentence below and its logical translation;

12a Mary a- bhururuts- a kaiti

1aMary 1SM fly-CAUS TV kite

'Mary flew the kite'

b ( $\exists \mathrm{e})$ [Agent(e,Mary) \& Cul(e) \& ( $\left.\exists \mathrm{e}^{\prime}\right)[$ bhururutsa(e') \& Cul(e') \& Theme(e',kite) \&

CAUSE(e,e')]]

This sentence is a direct translation of Mary flew the kite. Adopting Parsons' analysis to explicate an event semantics approach to causative would herald some problems. The major challenge emanates from the idea of nature of the language which is highly morphologically agglutinative. Ignoring the derivational process that characterizes causativisation in Shona would result in not having an adequate representative of the causative phenomena. Here the complex verb is being treated in the same way as a simple non causative verb.

The other challenge that Shona data would have with Parsons' analysis is how to deal/ capture double objectivisation. If the causative verb is treated the same way as the simplex one, it would be difficult to show /represent the meaning change that the causative affix would have introduced especially on argument structure/ valence. As a result of this and probably a plethora of other reasons, this paper will adopt an analysis that best captures the nature of the language under investigation.

This paper treats Shona causatives as a complex predicate that is not only morphologically complex, but exhibit syntactic and semantic complexity as well. We follow the thesis that the causative suffix forms a complex predicate with the verb; together as one predicate they select an object. The complex predicate inherits properties of both predicates. Complex predicate formation preserves the semantic argument structure of both predicates and amalgamates them into one syntactic argument structure by various operations (e.g. argument composition, argument attraction, argument suppression, theta identification, late mapping and others). Thus, this paper will adopt Rothstein's (2004) approach.

Rothstein's approach has the advantage that she introduced a summing operation that treats the two events as subevents of a single macroevent. There is a constraint on the summing operation with secondary predicates that we adopt for complex predicates, namely Time-participant connectedness (TPCONNECT). Both events share a participant and the run time of the first event has to be the same as the run time of the second event; 
TPCONNECT $\left(\mathrm{e}_{1}, \mathrm{e}_{2}, \mathrm{y}\right)$ iff:

i. $\tau\left(\mathrm{e}_{1}\right)=\tau\left(\mathrm{e}_{2}\right)$ (i.e. the run time of $\mathrm{e}_{1}$ is the same as the run time of $\left.\mathrm{e}_{2}\right)$;

ii. $e_{1}$ and $e_{2}$ share a participant $y$.

TPCONNECT holds between the culmination of the first event Cul $\left(\mathrm{e}_{1}\right)$ and $\left(\mathrm{e}_{2}\right)$. Since the culmination of an accomplishment predicate is assumed to be determined by what happens to its theme, this is the participant that has to be shared. The external argument of the noncausative predicate can become a derived internal argument of the verb when both predicates are combined into one complex predicate.

\section{Shona Causatives}

Now let us consider Shona data and how the underlying event structure treats Shona causatives. Sentence (13a) is a noncausative transitive sentence, which, when causativised assumes the form in sentence (13b) that is syntactically a double object construction. Such phenomenon is widespread in the Shona language and Bantu languages in general.

13a Imbwa ya - dy - a sadza.

9dog 9SM eat TV 5porridge

' The dog to ate porridge.'

b John a - dy - is - a imbwa sadza.

1a-name 1SM eat CAUS TV 9dog 5porridge

'John caused the dog to eat porridge.'

We use the example (13) above to illustrate how Shona causatives are treated in the underlying event semantics theory. The account will show how the base verb causativises and then involve the basic combinatorial processes that obtain from the whole causativised sentences, thereby building a phrase structure tree. Let us consider the lexical entry of the base verb $d y-a$ (eat) and the formal translation of the sentence before cuasativisation, to the whole causativised counterpart (i.e. Example 13a and 13b above).

$$
14<\mathrm{d},<\mathrm{e}, \mathrm{t}>; \lambda \mathrm{y}[\lambda \mathrm{e}[\mathrm{dy}-\mathrm{a}(\mathrm{e}) \wedge \operatorname{Agt}(\mathrm{e})=\mathrm{x} \wedge \mathrm{Th}(\mathrm{e})=\mathrm{y}]
$$

This structure shows that we have an individual entity $<d>$ and an event $e$ of $d y-a$ that culminates at time $t$ as represented by $<\mathrm{e}, \mathrm{t}>$ whose agent is $x$ and whose theme is $y$. (15) below shows the structure of the causativised verb formed through causative derivation and its combinatorial capacity.

$$
15 \lambda y \lambda x\left[\lambda e \left[\text { dy-is-a }\left(e_{2}\right) \wedge \operatorname{Arg} 1\left(e_{2}\right)=z \wedge \operatorname{Arg} 2\left(e_{2}\right)=x \wedge \operatorname{Th}\left(e_{2}\right)=y\right.\right.
$$

This reads as that there is another subevent, termed $\left(\mathrm{e}_{2}\right)$ that is the verb dyisa and Argument 1 (Arg 1) of the event is $z$, the newly added predicate and $\operatorname{Arg} 2$ of $\left(\mathrm{e}_{2}\right)$ is $x$, which happens to be the Agent of the noncausative verb and the theme of the subevent is $y$, the same theme as that of the noncausative verb. After applying the predicate formation rule indicated by $\lambda \mathrm{P}$, we 
get the event structure shown below.

$$
\begin{aligned}
16 & <\mathrm{d},<<\mathrm{d}<\mathrm{e}, \mathrm{t}>,<\mathrm{e}, \mathrm{t}>> \\
& \lambda \mathrm{x} \lambda \mathrm{y}\left[\lambda \mathrm { p } \left[\lambda \mathrm { e } \left[\exists \mathrm { e } _ { 1 } \left[\exists \mathrm { e } _ { 2 } \left[\mathrm{e}={ }^{\mathrm{s}}\left(\mathrm{e}_{1} \cup \mathrm{e}_{2}\right) \wedge \mathrm{dy}-\mathrm{a}\left(\mathrm{e}_{1}\right) \wedge \operatorname{Agt} \quad\left(\mathrm{e}_{1}\right)=\mathrm{x} \wedge \mathrm{Th} \quad\left(\mathrm{e}_{1}\right)=\mathrm{y} \wedge\right.\right.\right.\right.\right. \text {-is } \\
& \operatorname{CAUS}\left(\mathrm{e}_{2}\right) \wedge \operatorname{Arg} 1\left(\mathrm{e}_{2}\right)=\mathrm{z} \wedge \operatorname{Arg} 2\left(\mathrm{e}_{2}\right)=\operatorname{Agt}\left(\mathrm{e}_{1}\right) \wedge \operatorname{Th}\left(\mathrm{e}_{2}\right)=\operatorname{Th}\left(\mathrm{e}_{1}\right)
\end{aligned}
$$

Inferring from the above structure, we have two individual entities represented by two letter (d) in the structure $<\mathrm{d},<<\mathrm{d}<\mathrm{e}, \mathrm{t}>,<\mathrm{e}, \mathrm{t}>>$. The two (d) entities are the two lambda abstracted objects that the causative verb dyi-sa can project. We also have Simpson's Law in place (Simpson, 1983): The external argument $x$ of the noncausative predicate functions as the internal argument of the causative verbal predicate. The distinguishing property between the simple noncausative and complex causative event types is the property of S-cumulativity, which holds if two events of the same type can be summed to form a singular (singleton) event.

Following Rothstein (2004), $e$ is going to be treated as an eventuality, that is, both events and states. A complex eventuality $e$ which in this case is the causative sentence is a product of the sum of two subevents, the noncausative and the causative one, as illustrated by the part-structure $\left[\mathrm{e}^{\mathrm{s}}\left(\mathrm{e}_{1} \cup \mathrm{e}_{2}\right)\right]$ in the structure in (16) above. The intended interpretation is that, as Putstejovsky (2006:39-40) would put it, $e$ is an event containing two subevents $e_{1}$ and $e_{2}$, where the first temporally precedes the second and there are no other events locally contained in event $e$. A summing operation treats the two events as subevents of a single macroevent. Within an event semantics framework temporal relations are captured through how events unfold in time (i.e. Actual time) and within the subeventual analysis, events can be in sequential, partial overlap.

The causative predicate in (16) above has the capacity to merge with individual elements that are part of its combinatorial elements. That is, the verb dyi-sa combines with one of the objects to form projection 1, an intermediate projection in Chomskyan terms, forming the phrase dyisa imbwa as shown in the structure (17) below;

17 Dyisa imbwa

$$
\begin{aligned}
& <\mathrm{d} ;<\mathrm{e}, \mathrm{t}>,<\mathrm{e}, \mathrm{t}>> \\
& \lambda \mathrm{x} \lambda \mathrm{P}\left[\lambda \mathrm { e } \left[\exists \mathrm { e } _ { 1 } \left[\exists \mathrm { e } _ { 2 } \left[\mathrm{e}={ }^{\mathrm{s}}\left(\mathrm{e}_{1} \cup \mathrm{e}_{2}\right) \wedge \mathrm{dy}-\mathrm{a}\left(\mathrm{e}_{1}\right) \wedge \operatorname{Agt}\left(\mathrm{e}_{1}\right)=\operatorname{imbwa} \wedge \operatorname{Th}\left(\mathrm{e}_{1}\right)=\mathrm{y} \wedge\right.\right.\right.\right. \text {-is } \\
& \operatorname{CAUS}\left(\mathrm{e}_{2}\right) \wedge \operatorname{Arg} 1\left(\mathrm{e}_{2}\right)=\mathrm{z} \wedge \operatorname{Arg} 2\left(\mathrm{e}_{2}\right)=\operatorname{imbwa} \wedge \operatorname{Th}\left(\mathrm{e}_{2}\right)=\operatorname{Th}\left(\mathrm{e}_{1}\right)
\end{aligned}
$$

Since the predicate dyi-sa has satisfied one of its individual combinatorial variables, we then cancel it out to confirm the satisfaction, thus we end up with only one (d) in the structure in (17) above. Since the Agent x of the noncausative and Arg 2 of the causative predicate have been satisfied, we then replace $x$ with imbwa. To achieve a maximal projection, the verb dyisa has to combine with another argument sadza as shown in (18) below;

18 dyisa imbwa sadza

$$
<\mathrm{e}, \mathrm{t}>
$$


$\lambda \mathrm{e}\left[\exists \mathrm{e}_{1}\left[\exists \mathrm{e}_{2}\left[\mathrm{e}={ }^{\mathrm{s}}\left(\mathrm{e}_{1} \cup \mathrm{e}_{2}\right) \wedge \mathrm{dy}-\mathrm{a}\left(\mathrm{e}_{1}\right) \wedge \operatorname{Agt}\left(\mathrm{e}_{1}\right)=\right.\right.\right.$ imbwa $\wedge \operatorname{Th}\left(\mathrm{e}_{1}\right)=\operatorname{sadza} \wedge$-is-CAUS ( $\left.\mathrm{e}_{2}\right) \wedge \operatorname{Arg} 1\left(\mathrm{e}_{2}\right)=\mathrm{z} \wedge \operatorname{Arg} 2\left(\mathrm{e}_{2}\right)=\mathrm{imbwa} \wedge \operatorname{Th}\left(\mathrm{e}_{2}\right)=\operatorname{sadza}$

From structure (18) we can decipher that the causative predicate has satisfied its combinatorial power (of internal arguments) as indicated by the presence of the two objects in the phrase. The argument sadza is the theme in both the noncausative and causative subevents.

We still have to account for $\operatorname{Arg} 1\left(\mathrm{e}_{2}\right)=\mathrm{z}$. At this stage there is need to apply the predicate formation rule to account for the external argument of the predicate. This can be indicated through the $\lambda$ operator on the external argument.

$$
\begin{aligned}
& 19<\mathrm{d},<\mathrm{e}, \mathrm{t}>>: \\
& \lambda z\left[\lambda \mathrm { e } \left[\exists \mathrm { e } _ { 1 } \left[\exists \mathrm { e } _ { 2 } \left[\mathrm{e}={ }^{\mathrm{s}}\left(\mathrm{e}_{1} \cup \mathrm{e}_{2}\right) \wedge \mathrm{dy}-\mathrm{a}\left(\mathrm{e}_{1}\right) \wedge \operatorname{Agt}\left(\mathrm{e}_{1}\right)=\operatorname{imbwa} \wedge \operatorname{Th}\left(\mathrm{e}_{1}\right)=\operatorname{sadza} \wedge\right.\right.\right.\right. \text {-is-CA } \\
& \mathrm{US}\left(\mathrm{e}_{2}\right) \wedge \operatorname{Arg} 1\left(\mathrm{e}_{2}\right)=\mathrm{z} \wedge \operatorname{Arg} 2\left(\mathrm{e}_{2}\right)=\operatorname{imbwa} \wedge \operatorname{Th}\left(\mathrm{e}_{2}\right)=\operatorname{sadza}
\end{aligned}
$$

The result of the predicate formation rule shows that there is need to satisfy an individual variable as indicated by $[<\mathrm{d},<\mathrm{e}, \mathrm{t}>>]$. It is part of the causative predicate's projection, known as the 'Extended Projection Principle ${ }^{2}$ '(EPP) that caters for external arguments (specifiers). Upon satisfying the external argument John, we have a structure like (20) below.

$$
\begin{aligned}
20< & <e, t> \\
& \lambda e\left[\exists e _ { 1 } \left[\exists e _ { 2 } \left[e={ }^{s}\left(e_{1} \cup e_{2}\right) \wedge d y-a\left(e_{1}\right) \wedge \operatorname{Agt}\left(e_{1}\right)=\operatorname{imbwa} \wedge \operatorname{Th}\left(e_{1}\right)=\operatorname{sadza} \wedge-\operatorname{is}-\operatorname{CAUS}\left(e_{2}\right)\right.\right.\right. \\
& \wedge \operatorname{Arg} 1\left(e_{2}\right)=\operatorname{John} \wedge \operatorname{Arg} 2\left(e_{2}\right)=\operatorname{imbwa} \wedge \operatorname{Th}\left(e_{2}\right)=\operatorname{sadza}
\end{aligned}
$$

This is the highest point of the phrase structure tree save for the fact that we have to apply the Existential quantifier closure rule to get rid of the lambda operator, achieving the final structure like the one below.

$21 \exists \mathrm{e}\left[\exists \mathrm{e}_{1}\left[\exists \mathrm{e}_{2}\left[\mathrm{e}=\mathrm{s}\left(\mathrm{e}_{1} \cup \mathrm{e}_{2}\right) \wedge \mathrm{dy}-\mathrm{a}\left(\mathrm{e}_{1}\right) \wedge \operatorname{Agt}\left(\mathrm{e}_{1}\right)=\mathrm{imbwa} \wedge \mathrm{Th}\left(\mathrm{e}_{1}\right)=\operatorname{sadza} \wedge\right.\right.\right.$-is-

$$
\operatorname{CAUS}\left(\mathrm{e}_{2}\right) \wedge \operatorname{Arg} 1\left(\mathrm{e}_{2}\right)=\operatorname{John} \wedge \operatorname{Arg} 2\left(\mathrm{e}_{2}\right)=\operatorname{imbwa} \wedge \operatorname{Th}\left(\mathrm{e}_{2}\right)=\text { sadza }
$$

There is a singular event which is the sum of an event of dog eating sadza and John making it eat (cause it). The base verb and the CAUSE predicate together form a complex predicate (semantically), which specifies a single event. The whole tree projection is displayed below in figure 2 below.

\footnotetext{
${ }^{2}$ The EPP is borrowed ad verbatim from Principles and Parameters/Government and Binding theory (Chomsky 1981)
} 
$\exists \mathrm{e}\left[\exists \mathrm{e}_{1}\left[\exists \mathrm{e}_{2}\left[\mathrm{e}^{\mathrm{e}}{ }^{\mathrm{s}}\left(\mathrm{e}_{1} \cup \mathrm{e}_{2}\right) \wedge \mathrm{dy}-\mathrm{a}\left(\mathrm{e}_{1}\right) \wedge \operatorname{Agt}\left(\mathrm{e}_{1}\right)=\right.\right.\right.$ imbwa $\wedge \mathrm{Th}\left(\mathrm{e}_{1}\right)=\operatorname{sadza} \wedge$-is-CAUS $\left(\mathrm{e}_{2}\right) \wedge \operatorname{Arg} 1$ $\left(\mathrm{e}_{2}\right)=\operatorname{John} \wedge \operatorname{Arg} 2\left(\mathrm{e}_{2}\right)=$ imbwa $\wedge \operatorname{Th}\left(\mathrm{e}_{2}\right)=$ sadza

\section{EXISTENTIAL QUANTIFIER CLOSURE}

Maximal projection

$<\mathrm{e}, \mathrm{t}>\lambda \mathrm{e}\left[\exists \mathrm{e}_{1}\left[\exists \mathrm{e}_{2}\left[\mathrm{e}={ }^{\mathrm{s}}\left(\mathrm{e}_{1} \cup \mathrm{e}_{2}\right) \wedge \mathrm{dy}-\mathrm{a}\left(\mathrm{e}_{1}\right) \wedge \operatorname{Agt}\left(\mathrm{e}_{1}\right)=\mathrm{imbwa} \wedge \mathrm{Th}\left(\mathrm{e}_{1}\right)=\operatorname{sadza} \wedge-\right.\right.\right.$ is-CAUS $\left(\mathrm{e}_{2}\right) \wedge$ $\operatorname{Arg} 1\left(\mathrm{e}_{2}\right)=\operatorname{John} \wedge \operatorname{Arg} 2\left(\mathrm{e}_{2}\right)=\mathrm{imbwa} \wedge \mathrm{Th}\left(\mathrm{e}_{2}\right)=$ sadza

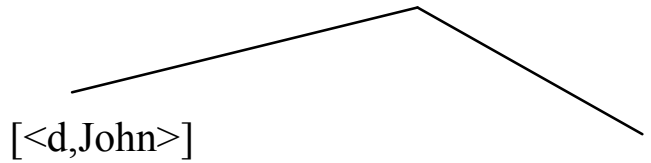

$$
\begin{aligned}
& <\mathrm{d},<\mathrm{e}, \mathrm{t}>> \\
& \lambda \mathrm{z}\left[\lambda \mathrm { e } \left[\exists \mathrm { e } _ { 1 } \left[\exists \mathrm { e } _ { 2 } \left[\mathrm{e}^{\mathrm{s}}\left(\mathrm{e}_{1} \cup \mathrm{e}_{2}\right) \wedge \mathrm{dy}-\mathrm{a}\left(\mathrm{e}_{1}\right) \wedge\right.\right.\right.\right. \\
& \operatorname{Agt}\left(\mathrm{e}_{1}\right)=\operatorname{imbwa} \wedge \operatorname{Th}\left(\mathrm{e}_{1}\right)=\operatorname{sadza} \wedge-\mathrm{is}-\mathrm{CAUS} \\
& \left(\mathrm{e}_{2}\right) \wedge \operatorname{Arg} 1\left(\mathrm{e}_{2}\right)=\mathrm{z} \wedge \operatorname{Arg} 2\left(\mathrm{e}_{2}\right)=\operatorname{imbwa} \wedge \mathrm{Th}\left(\mathrm{e}_{2}\right) \\
& =\operatorname{sadza}
\end{aligned}
$$

Projection 2 VP dyisa imbwa sadza

\section{PREDICATE FORMATION}

$<\mathrm{e}, \mathrm{t}>\quad \lambda \mathrm{e}\left[\exists \mathrm{e}_{1}\left[\exists \mathrm{e}_{2}\left[\mathrm{e}^{\mathrm{s}}{ }^{\mathrm{s}}\left(\mathrm{e}_{1} \cup \mathrm{e}_{2}\right) \wedge \mathrm{dy}-\mathrm{a}\left(\mathrm{e}_{1}\right) \wedge \operatorname{Agt}\left(\mathrm{e}_{1}\right)=\right.\right.\right.$ imbwa

$\wedge \mathrm{Th}\left(\mathrm{e}_{1}\right)=$ sadza $\wedge$-is- $\operatorname{CAUS}\left(\mathrm{e}_{2}\right) \wedge \operatorname{Arg} 1\left(\mathrm{e}_{2}\right)=\mathrm{z} \wedge \operatorname{Arg} 2\left(\mathrm{e}_{2}\right)$

$=$ imbwa $\wedge \mathrm{Th}\left(\mathrm{e}_{2}\right)=$ sadza

Projection 1 Dyisa imbwa $<\mathrm{d} ;<\mathrm{e}, \mathrm{t}>,<\mathrm{e}, \mathrm{t}>>$

$\lambda \times \lambda \mathrm{P}\left[\lambda \mathrm{e}\left[\exists \mathrm{e}_{1}\left[\exists \mathrm{e}_{2}\left[\mathrm{e}={ }^{\mathrm{s}}\left(\mathrm{e}_{1} \cup \mathrm{e}_{2}\right) \wedge \mathrm{dy}-\mathrm{a}\left(\mathrm{e}_{1}\right) \wedge\right.\right.\right.\right.$

$\operatorname{Agt}\left(\mathrm{e}_{1}\right)=\operatorname{imbwa} \wedge \mathrm{Th}\left(\mathrm{e}_{1}\right)=\mathrm{y} \wedge$-is-CAUS $\left(\mathrm{e}_{2}\right) \wedge$

$\operatorname{Arg} 1\left(\mathrm{e}_{2}\right)=\mathrm{z} \wedge \operatorname{Arg} 2\left(\mathrm{e}_{2}\right)=\mathrm{imbwa} \wedge \mathrm{Th}\left(\mathrm{e}_{2}\right)=\operatorname{Th}\left(\mathrm{e}_{1}\right)$

$<\mathrm{d},<<\mathrm{d}<\mathrm{e}, \mathrm{t}>,<\mathrm{e}, \mathrm{t}>>$

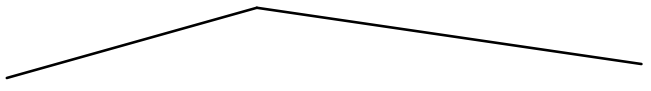

$\lambda \mathrm{x} \lambda \mathrm{y}\left[\lambda \mathrm{p}\left[\lambda \mathrm{e}\left[\exists \mathrm{e}_{1}\left[\exists \mathrm{e}_{2}\left[\mathrm{e}={ }^{\mathrm{s}}\left(\mathrm{e}_{1} \cup \mathrm{e}_{2}\right) \wedge \mathrm{dy}-\mathrm{a}\left(\mathrm{e}_{1}\right) \wedge\right.\right.\right.\right.\right.$

$[$ imbwa $<$ d; $<\mathrm{e}, \mathrm{t}>]$

$\operatorname{Agt}\left(\mathrm{e}_{1}\right)=\mathrm{x} \wedge$ Th $\left(\mathrm{e}_{1}\right)=\mathrm{y} \wedge$-is-CAUS $\left(\mathrm{e}_{2}\right) \wedge$

$\operatorname{Arg} 1\left(\mathrm{e}_{2}\right)=\mathrm{z} \wedge \operatorname{Arg} 2\left(\mathrm{e}_{2}\right)=\operatorname{Agt}\left(\mathrm{e}_{1}\right) \wedge \operatorname{Th}\left(\mathrm{e}_{2}\right)=\operatorname{Th}\left(\mathrm{e}_{1}\right)$

$$
\text { PREDICATE FORMATION }
$$

$\lambda y \lambda x\left[\lambda e\left[\right.\right.$ dy-is-a $\left(e_{2}\right) \wedge \operatorname{Arg} 1\left(e_{2}\right)=z \wedge \operatorname{Arg} 2\left(e_{2}\right)=x \wedge \operatorname{Th}\left(e_{2}\right)=y$

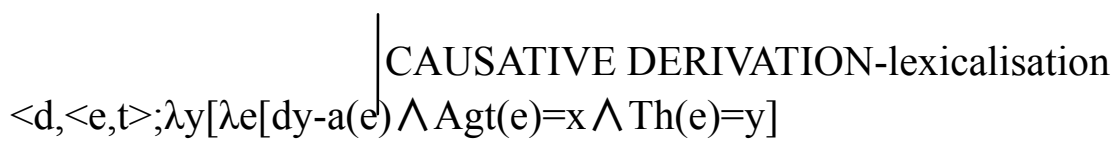

Figure 2. Phrase structure tree for a causativised sentence

The tree diagram above exposes two major processes namely causative derivation and predicate formation. The two processes, particularly causative derivation, show that 
causativisation occurs before any syntactic processes come into effect, thereby supporting the fact that the causative derivational suffix is a lexical process that attaches in the lexicon. The first level of predicate formation occurs after the causative suffix attaches to the base verb forming a complex predicate which then spells out its own combinatorial capacity different from the non-causative predicate. Soon after the second projection that results in the Verb Phrase dyisa imbwa sadza, we apply the predicate formation rule, making it possible for the specifier to merge with the VP, forming a maximal projection. We apply the existential quantifier closure rule to get rid of the lambda operator since it is an abstraction that only helped us to identify the combinatorial capabilities of the predicate, thus the need for an 'empirical' quantifier that identifies with an individual in the universe of discourse.

\section{Conclusions}

Our approach bases on the idea that the grammar of natural language structures certain of the events represented by verbs into complex events, with a causative outer event and a change-of-state inner event. Thus causativisation involves complex predication that result in complex event structure. However, recently constructionists have claimed that causation is not a relation between an individual agent assigned by the verb and a proposition but stands in relation between two events. Moreover, in their decompositional approach where each subevent can be decomposed as an event constituent, they present the mapping strategy between event arguments and syntactic arguments.

In Shona language, the component that expresses the meaning of a causing event is overtly realized. However, the result state is not expressed by special morphology, but rather is incorporated into the meaning of specific verbs in causative constructions. The meaning of causation is encoded in the result head by interpreting it as building a causal relation in the semantic implicature. We conclude that Shona causative constructions are complex predicates that are constrained by time-participant connectedness, where the time difference between the first subevent $e_{1}$ and the second subevent $e_{2}$ may be simultaneous in case of direct causation and overlapping in the case of indirect causation, with varying degrees depending on the base verb and the effect perceived on the theme.

\section{References}

Chomsky, N. (1981). Lectures on Government and Binding. Dordrecht: Foris

Chomsky, N. A. (1971). "Constraints on Transformations” In S. Anderson and P, Kiparsky (Eds.). Festschrift for Morris Halle. New York: Holt, Rinehart and Winston.

Davidson, D. (1967). “The Logical Form of Action Sentences," in N. Rescher (ed.) The Logic of Decision and Action. (pp. 81-120) Pittsburgh: University of Pittsburgh Press.

Dowty, D.R. (1979). Word Meaning and Montague Grammar, Reidel, Dordrecht.

Higginbotham, J. (1989). "Elucidations of Meaning," Linguistics and Philosophy 12: 465-517.

Hukari, T. E., \& Levine, R. D. (1994). Adjunct extraction. In Proceedings of the Twelfth 
Annual West Coast Conference on Formal Linguistics, pages 283-298.

Hukari, T. E., \& Levine, R. D. (1995). Adjunct extraction. Journal of Linguistics, 31:195-226. DOI: $10.1017 / \mathrm{S} 0022226700015590$

Kathol A., Przepiorkowski A., Tseng J. ( 2011). 'Advanced Topics in Head-Driven Phrase Structure Grammar". In: Robert D. Borsley and Kersti Boerjars, eds.2011.Non-Transformational Syntax: Formal and Explicit Models of Grammar. West Sussex, UK: Wiley-Blackwell, 54-111. http://dx.doi.org/10.1002/9781444395037.

Kemmer. S \& A. Verhagen. (1994). 'The grammar of causatives and the conceptual structure of events' Cognitive Linguistics 5-2, 115-156, Walter de Gruyter.

Lakoff, G.P. (1970). Irregularity in Syntax. NY: Holt, Rinehart and Winston.

McCawley, J.D. (1968). "Lexical Insertion in a Transformational Grammar without Deep Structures" Chicago Linguistic Society 4, 71-80.

Parsons, T. (1990). Events in the Semantics of English: A Study in Subatomic Semantics. Current Studies in Linguistics Series 19. Cambridge, MA: MIT Press.

Pustejovsky, J. (2006). The syntax of event structure. In Inderjeet Mani, James Pustejovsky, and Rob Gaizauskas (eds.). The Language of Time. A reader. Oxford University Press.

Rothstein, S. (2004). Structuring Events: A Study in the Semantics of Lexical Aspect. Oxford: Blackwell. http://dx.doi.org/10.1002/9780470759127.fmatter

Shibatani, M. (1976). The grammar of causative constructions: A conspectus. In Masayoshi Shibatani (ed.): The grammar of causative constructions. Syntax and Semantics, vol. 6. New York: Academic Press, 1-40.

Simpson, J. (1983). Resultatives. In Papers in Lexical Functional Grammar, ed. Lori Levin, Malka Rappaport, and Annie Else Zaenen, 143-157. Bloomington: The Indiana University Linguistics Club. 